inflammation, not of any particular set of fibres or cells, but of a whole section of the spinal cord. Such cases present a great variety of symptoms, which I need not now go into; but amongst them are alterations in the reflexes, which enable us to localise the disease and assist us also in prognosis. It may be generally accepted that in such cases the reflexes are obliterated in that part of the cord which is diseased, while they are exaggerated below. Clearly the reason for this must be that the lesion destroys one or more factor; of the reflex arc, and so abolishes the reflexes in connexion with it, while below the lesion only the pyramidal tracts are diseased, and therefore the reflexes below are exaggeraterl. The cells which preside over the nutrition of the pyranidal tract are the motor cells in the cortex of the brain, and when disease separates a part of the nerve from its centre ab we it degenerates. Hence, whenever a myelitis injures the pyramilal tract at any point, the tract degenerates below. It will thus be understood how by examining where reflexes are diminished or absent, and where exagrerated, we may succeed in fixing the position of a myelitis in the cord. While, however, we remember the importance of exaggerated reflexes, we must not lay undue weight upon them. $\mathrm{I} t$ is always necessary to keep in mind that what appears to be exaggeration to an observer unfamiliar with the phenomena may appear to be variation within the normal limits to the experienced. As I have said before, the fixing of the normal is the difficulty, and can only be effected by frequent observation of people free from gross disease of the nervous system. A very striking instance of the excitability of the cells of the spinal cord, and the readiness with which reflex muscular contractions are produced through them when uncontrolled by the fibres of the pyramidal tract, is to be found in the case of young children. Every medical man is familiar with the convulsive diseases of childhood, such as laryngismus stridulus, tetany, twitchings of various muscles, and more or less general convulsions; and he is quite rightly accustomed to look upon them far less serionsly than similar affections in adults. And why? Comparatively recent investigations have given us an insight in to the true canse of this difference between young and adult persons. Virchow says that children afford fine examples of an almost pure spinal cord existence ("ein prächtiges Beispiel eines fast reinen Rückenmarkswesen"); for it is now known that the fibres of the pyramidal tract are very late in development, so that in early ehildhood they are in a rudimentary condition. But as these fibres directly control or inhibit the reflex activity of the centres in the anterior cornua of the cord, the latter must, in the absence of them, run riot, as it were. Consequently, very feeble afferent stimuli, which in ardults would be incapable of producing muscular contractions, do so very readily in children.

4. The special condition of the reflexes in certain cases of cerebral disecuse. - It is very curious that, al though the same mechanism seems to preside over the superficial and deep reflexes, they do not alter in a corresponding way in some cases of cerebral disease. I refer especially to hemiplegia caused by embolism, thrombosis, or hæmorrhage. In these conditions the deep reflexes are exaggerated, the superficial absent or diminished. We have no satisfactory explanation of this fact at present, but, nevertheless, from a practical, diagnostic point of view, it is rery important. A rnedical man is often called to the bedside of an unconscious person. He is informed that the attack has been quite sudien. Nothing, probably, is to be made out except that the patient is unconscious, breathing stertorously, and that all his limbs are tlaccid and his pupils widely dilated and motionless. If this state of coma is very intense, all the reflexes may be absent, both superficial and deep. But if the conta be less marked, one may very likely find that on one side of the body the superficial reflexes are present, and on the other absent or much diminished, and the deep reflexes exaggerated. If this be so, the medical man will be able to say that if the patient recovers from his coma he will be hemiplegic; for, although the same symptoms may be present in an ordinary epileptic fit, they only last for a short time. The prolonged absence of all reflexes in coma is evidence of the severity of the attack, and makes the prognosis correspondingly bed. When the unconsciousness passes off, the deep reflexes on the paralysed side are exaggerated, the superficial diminisheu. As time goes on and the case becomes chronic, clonus may supervene; and if there be in such a case exaggerated deep reflexes, clonus, and some constant rigidity, we may say that degeneration of the corresponding pyramidal tract has occurred, and that the hemiplegia will not pass away. But exaggerated reflexes and clonus without rigidity, although of bad omen, do not necessarily indicate incurable hemiplegia; but when rigidity is added, they probably do.

In this short communication upon the diagnostic value of the reflexes which I have now completed, my endeavour has been rather to point out the rational anatomical and physiological grounds which should guide us in their use at the bedside than to present an exhanstive paper on their condition in all manner of diseases. Books can be referred to when such information is required. But the important thing for practical men to know is how to get the information for themselves, and how to interpret rationally that information when obtained.

Portland-place, $w$.

\section{NOTE ON A CASE OF CHOLECYSTOTOMY.}

BY LAWSON TAIT, LL.D., F.R.C.S.,

PROFESSOR OF GYYACOLOGY IN QULEX's COLLEGE, BIRMLYGHAM.

M. $\mathbf{S}-$, aged forty, was sent to me in November, 1886 , by Dr. Bond of Brinklow with a large abdominal tumour, which presented all the appearances and physical signs of a parovarian cyst, and as such I had no hesitation in regarding it. I opened the abdomen on the 26 th of the month by an incision about two inches long. On emptying the tumour, I found, to ny amazement, that it was a gall-bladder enormously distended. I enlarged the abdominal sperture and the opening into the cyst to a sufficient size to allow my hand to enter, passing it up towards the liver. I found a gall-stone as large as a filbert nut impacted in the neck of the gall-bladder. This I removed with a good deal of difficulty, and I also found in the cavity two or three smaller calculi. I stitched the opening of the call-bladder to the opening in the abdominal wall, which of course had been made in the original position in the middle line close above the pubis, and I then inserted a drainage tube. Bile began to How from the tube on the morning of the third day after the operation. I removed the stitches and drainage tube on the sixth dav, and the patient left the hospital with the wound perfectly healed on Dec. 12th. I saw her on Jan. 17th, 1889, and she had remained in perfect health, with the wound perfectly closed, and not the slightest trace of her old trouble.

The interest of this case consists first of all in the enormous distension of the gall-bladder, for the measured quantity of its contents amounted to nearly eleven pints, consisting of the usual clear gluey fluid. It certainly is an astounding record to make that a distended gall-bladder was mistaken for a parovarian cyst, and that the operation of cholecystotomy was performed by an opening in the middle line below the umbilicus.

The record of this case enables me to allude to a paper by Dr. A. Depage in the Brussels Medical Journal (abstraoted on page 89 of the current volume of THE LANCET), in which the authorcontrasts the operation of cholecystotomy with that of cholecystectomy. For this purpose he gathers together heterogeneous collection of statisties which I venture to say is of no value whatever. He has collected seventy-two cases of cholecystotomy as I perform it and gives eleven deaths, but it is a little difficult to say how he has omitted the number of cases performed in Birmingham, and already published, amounting to fifty-seven cases, with three deaths, leaving only in his list fifteen other cases, with eight deaths. This statement completely indicates the utter futility of the method of displaying figures adopted by Dr. Depage and many others. By such a method of display he shows what can be done in making a perfectly simple operation appear to have a heary mortality. But that is not displaying the mortality of the operation, for it must be clearly underswood that there is a great difference between the mortality of a large number of operations collected from the work of operators who have done one or two operations each, and a collection of operations done by one particular surgeon, or by two or three selected on account of their experience. These latter will give the mortality of the operation, whilst the other method will give the nortality of a bundle of individual and nostly inexperienced operators. It would be just as fair to exhibit a collection of the schoolboy drawings of our present Royal Academicans and say that these 
represent the British art of the period as to collect such a bundle of statistics as Dr. Depage has done for the serious discussion of the mortality of two operations.

I have now performed fifty-four cholecystotomies, with two deaths; and, as I have already said in the columns of THE LANCET, these deaths were not in the least degree attributable to the operation, but simply to the progress of the disease; we may take it, therefore, that the true mortality of cholecystotomy is not more at present than 4 per cent. Of the cases operated upon so far there has been not a single case of recurrence of the disease, so that this argument which is put forward in favour of cholecystectomy has no foundation whatever. As a matter of fact, gall-stone is not a disease of the gall-bladder, for it is perfectly evident that the stones are not formed there, although it is true that there they grow ; just as we know that in the great bulk of cases stone in the bladder is not a disease of the bladder originally, for the stones are in most instances formed in the kidney. Biliary fistula after cholecystotomy can only be permanent when the operation happens to have been performed at a time when a gall-stone was impacted in the common duct-at least that is my experience ; and I can hardly imagine any other condition than obstruction of the common duct making this condition permanent. In three of my cases I have crushed this obstructing gall-stone, and have succeeded in getting a free road through the common duct. In one case I did not succeed; the patient, after living some years with a biliary fistula, died of phthisis, though we have every reason to believe that the phthisis was a condition perfectly independent of the biliary fistula. On post-mortem examination there was found a series of gall-stones obstructing the common duct, only one of which I had succeeded in breaking up. It must be evident to the least skilled observer that in these cases removal of the gallbladder would have been the most foolish of all possible proceedings, for the bile must have regurgitated immediately into the peritoneum. The cases alluded to by Dr. Depage, where the biliary fistula was alleged to remain permanently, really constitute the strongest of all arguments against the operation of cholecystectomy, and of this operation I may also say that it is one which can be performed with greatest ease when there is no need for it-that is to say, when the gall-bladder is free from adhesions and perfectly healthy; but in those conditions where it might really be found advantageous - that is, where the gall-bladder is in a condition of chronic suppuration and greatly thickened by disease-the operation would be an absolute impossibility in the living body. Therefore, before we can judge as to its mortality, we must know not only how many cases have been performed, and what the mortality of these is, but we must know how many times it has been begun and left unfinished, and I venture to say that the list will be found to be an inmensely heavy one. I conclude, therefore, that the statistics of Dr. Depage are so misleading as to be of no value whatever for the purpose of determining the relative values of the two operations.

Birmingham.

\section{ON THE}

\section{INFLUENCE OF THE CORPUS STRIATUM AND OPTIC THALAMUS UPON THE BODILY TEMPERATURE.}

BY W. HALE WHITE, M.D., F.R.C.P., SENIOR ASSISTANT PHYSICIAN TO, AND LECTURER ON MATERIA MEDICA AT, GUY'S HOSPITAL.

MANY observers have shown that the corpus striatum has an important modifying influence upon the temperature of the body. Aronsohn and Sachs ${ }^{1}$ made many experiments, and always obtained a rise of temperature when the corpus striatum was injured. Richet ${ }^{2}$ also performed similar experiments, with the same results. Ott ${ }^{3}$ has done much work at the subject, and in one experiment obtained a rise of $7^{\circ} \mathrm{F}$. as a result of injury to the corpus striatum ; he also showed that the optic thalamus likewise has an in-

Pfluiger's Archiv, Oct. 1885; and Deut. Med. Woch., 1884. Bulletins de la Société de Biologie.

3 Journal of Nervous Diseases, April, 1884 (Philadephia). Medical News, July, 1885. Journal of Nervous Diseases, July, 1887, and February, 1888. Therapeutic Gazette, Sept. 1887. Brain, April, 1889. fluence upon the bodily temperature, which rises after injuries to it. The fact that injury of the corpus striatum causes a rise of temperature has also been confirmed by Gerard $^{4}$ and Baginsky. ${ }^{5}$ At a recent meeting of the Neuroloyical Society I detailed a number of experiments which confirmed those of previous observers, proved that lesions of the optic thalamus likewise produced a rise of temperature of the body, and that destruction of the white matter had no effect upon the bodily temperature. ${ }^{6}$ The following cases are of interest as confirming these experiments.

CASE 1. Bilateral Softening of both Corpora Striata.H. L_ aged fifty-one, was under my care in Guy's Hospital. About a year before admission he noticed that his legs dragged. He took to his bed for three months, but gradually regained power and got about again. The legs remained weak, and slowly became more and more so, till fourteen days before admission he suddenly lost nearly all power over them, and had to be put to bed. His arms have been getting a little weak, and his memory is slightly deficient.

On admission his speech was slow. There was considerable paresis of all his muscles, especially the legs. The knee-jerks were well marked, and in places sensation was slightly impaired. His temperature for the first seven weeks was never over $98.4^{\circ}$; usually it was $97.8^{\circ}$. On April 5th (seven weeks after admission), whilst at the watercloset, he fell off the seat. He says he was not unconscious, but on being put to bed he became so, and his temperature rose to $1024^{\circ}$. He remained unconscious till his death, on April 10th. The accompanvino rhart shows that from April 5th to his death the temperature was raised:

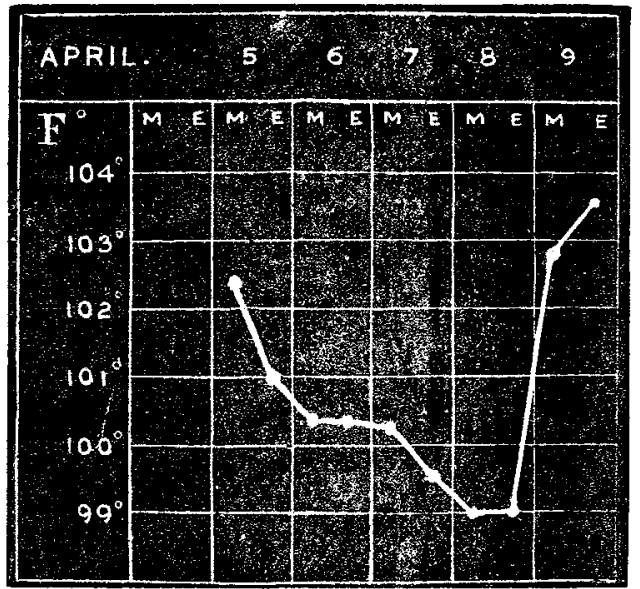

The post-mortem examination showed that the arteries were atheromatous. Externally the brain appeared healthy. On cutting it, two large patches of yellowish-white softening were found. On the right side the patch was an inch in length from before backwards, occupying the posterior position of the internal capsule, extending backwards as far as the posterior limit of the capsule, but not quite as far forwards as the genu. On the left side there was a large patch in the internal capsule, affecting the genu and posterior limb, but not extending into the anterior limb, and not quite reaching the posterior extremity of the posterior limb. Both these patches extended for a short distance into the adjacent optic thalami and corpora striata to a slight degree. The kidneys were slightly granular.

CAsE 2. Softening of the Corpus Striatum.-B. G-, aged fifty-six, was admitted under my care into Guy's Hospital. He had had rheumatic fever in his youth. Shortly before admission he had complained of nunibness in the left arm and leg, and a few minutes afterwards he fell down.

On admission he was conscious. There was complete paralysis of the left arm, leg, and face, save the forehead. There was some ptosis of the left eyelid. The tongue pointed to the left; the head and eyes turned to the richt. The left knee-jerk was exaggerated. There was complete hemianæsthesia on the left side of the head and trunk, and of the left upper and lower extrenities, except over a small spot on the outer side of the ankle. The left conjunctiva was insensitive. Over the hemiana-thetic areas the sensation of touch and pain and the power of discrimination of heat and cold, were not perceptible. There was left homonymous

4 Arch. de Physiologie, 1886. 5 Virchow's Archiv, November, 1886. 6 A full account of these experimests will appear in the nextnumber of the Journal of Physiology. 